\title{
The Application of Semantic Theories in ELT in Chinese Middle School ----Semantic Theories and Lexical Teaching
}

\author{
Li Ma \\ East China Jiaotong University, Nanchang, Jiangxi, China \\ 57627550@qq.com
}

Keywords: Lexical teaching; Semantic theories; Direct; Explanation; Contextual; Behaviorism.

\begin{abstract}
This paper focuses on the applications of semantic theories in English lexical teaching. With the introduction of some failures in lexical teaching and bad results students get, the importance of good lexical teaching methods is obvious. Thanks to the unique characteristics of four semantic theories, the paper proposes four lexical teaching methods. For illustration of how these methods work, some examples are analyzed.
\end{abstract}

\section{Introduction}

With the development of society and science, the English vocabulary is becoming larger and larger. Therefore, it is very important to enlarge the vocabulary for an English learner because it will affect the understanding and using of the language. As for the English teacher, it is also important to find out the ways to teach English words effectively. Many linguists have been probing whether linguistic theories could be good for English Language Teaching especially lexical teaching. And they discovered that if English teacher could use some of semantic theories properly in ELT, it will help students in understanding, using and appreciating words.

\section{Several Failures in Lexical Teaching}

In lexical teaching, teachers always use some wrong ways. To sum up all the failures, these two have appeared in very high frequency.

Explain the Meaning of Words without Paying Attention to the Context. For instance, when teachers teach 'seal', he or she may just explain that 'seal' means 'an aquatic animal or the king's stamp'. So, in the sentence 'the seal could not be found', students will be confused that which meaning of it should be employed. Teaching words in this way, students could not fully understand the connotation and usage of words, and also could lose the interests of English study

Overemphasize the Importance of Reciting the Vocabulary. In lexical review, many English teachers just ask students to recite the vocabulary. Though students could recite every word correctly, they still could not get good results in examinations.

Consequently, how to get rid of these failures in lexical teaching is becoming the major problem in ELT. Through analyzing four semantic theories, this paper tries to convey the relationship between four semantic theories and lexical teaching and introduce four lexical teaching methods when these four theories applied in lexical teaching.

\section{Four Semantic Theories and Their Applications in Lexical Teaching}

Various scholars have proposed a number of approaches to the study of meaning many years ago, such as naming theory, conceptualist theory and so on.[1] These theories are very helpful especially when they are applied in lexical teaching. Because the most important thing in language learning is the understanding of words. With the help of these theories, the process of teaching will become more convenient and easier.[2] Let's take a view on the four major semantic theories as well as their applications in lexical teaching one by one. 
The Naming Theory and LT. The Naming Theory is one of the oldest notions and also a very primitive one concerning meaning which proposed by the ancient Greek scholar Plato. According to this theory, the linguistic forms or the words used in a language are taken to be labels of the objects they stand for.[3] So, words are just names or labels for things. In other words, the semantic relationship holding between words and things is the relationship of naming. Therefore, when teacher applied this theory in LT, they can have a new lexical teaching method - the Direct Method, which makes a direct linkage between meaning and linguistic forms. That is to say, when teachers teach new words, they can use objects, pictures, gestures and other things. As we all know, objects are concrete and real, and could be seen and touched, therefore people can describe them from the aspects of quality, size, color and so on. If teacher apply the Naming Theory in lexical teaching, it will be easy for learners to understand and memorize the new words. Because when we use our visual perception or our imagination to the words with the objects in the real world, we will find it very easy to understand and memorize them. With the help of this method, the new words will turn to be so realistic to be understood. For example, when a teacher teaches the word watch, he or she can use a real watch to help the students understand the meaning of watch. And if a new lesson is about fruits, teachers would better bring some fruits to the class. Because there are many different names of fruits, students may find it difficult to understand and memorize those strange names. But if teachers use real fruits such as apple, orange, pear and so on, students will no longer have trouble in matching their names with real objects and memorize them with less difficulty. Sometimes teachers may find that some real objects are too big to bring it into classroom, teachers can use pictures instead of real objects. And the effect of using the Name theory in lexical teaching is also achieved since students will get the general idea of the word from the picture. And for those emotional adjectives, teachers could use gestures. For instance, when a teacher teaches the word smile, he or she can make the gesture of it. Through this gesture, students could understand the meaning of smile as well as the pronunciation of it. And from the teaching practice, we know that this Direct Method is very helpful, not only in helping them understand and memorize new words but also in arising students' interests of study. But this method is not useful in teaching all kind of words. Teachers would better use this method in teaching nouns and adjectives.

The Conceptualist Theory and LT. The conceptualist view holds that there is no direct link between a linguistic form and its referent, which means there is no direct link between language and the real word. In the interpretation of meaning, they are linked through the mediation of concepts in the mind. We can use the classic semantic triangle of significance which suggested by Ogden and Richard to illustrate this theory.

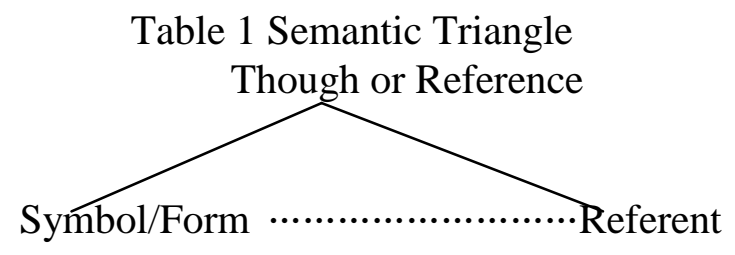

In this diagram, the symbol or form refers to the linguistic elements, the referent refers to the object in the word of experience, and the thought or reference refers to concept.[4] From the triangle, we know that there is no direct link between symbol and referent, the link is thought or reference, the concept of our mind. For example, the world 'dog' is directly associated with a certain concept in our mind, what a dog is like, but it is not directly linked to the particular dog mentioned in the sentence 'Jims dog is beautiful'. So we know the referent is a specific one, and the concept of dog is the meaning of it. In foreign language teaching, the concepts of words may vary in different languages. When teachers apply the Conceptualist Theory in lexical teaching, they could have a new method - the Explanation Method, which means using definition to explain the meaning of word. For example, the English word 'uncle' can be referred to 'father's brothers' or 'mother's brothers'. But in Chinese, we can't find a word identical with 'uncle', because this word needs to be translated 
accordingly to the different relationships between uncle and parents. From this we know that 'uncle' has different concepts in two languages. And English teachers should explain the word in English to let the students know its concept. This Explanation Method avoids the misunderstanding of words which is not totally equivalent with Chinese. Also this method enable students to understand the meaning accurately.

The Contextual Theory and LT. The Contextual Theory holds the view that one can derive meaning from or reduce meaning to observable contexts. The contexts can be divided into two kinds, the situational context and the linguistic context. As first, we should distinguish these two kinds of contexts. Situational context is non-linguistic and it refers to the particular spatiotemporal situation the utterances occur. The main components of it are place, time, speaker, hearer, the action they are performing at the time, the various objects and events existent in the situation. The linguistic context concerned with the probability of a word's co-occurrence or collocation with other words which forms part of the meaning of word, that precedes and follows a particular utterance a representative of this approach was the British linguist John Firth. As early as 1930's, he proposed the view that 'By regarding words as acts, events, habits, we limit our inquiry to what is objective in the group life of our fellows' and 'we shall know a word by the company it keeps.'[5]

Context is really helpful in the understanding of word's meaning. English teachers should make full use of both the situational context and linguistic context to get students to catch the correct meaning of words. Therefore, the method of applying the Contextual Theory in lexical teaching could be called the Context Teaching Method.

Let's take a view of the application of this teaching method. As we know that the polysemic words are those words with more then one meaning. The sameness in form makes it difficult for students to identify the meaning. Take 'bank' for an example, we are familiar with at least two meanings of the word as a noun. One is 'land along each side of a river or canal, ground near the river' and the other is 'the establishment for keeping money and valuables safely, the money being paid out on customer's order by means of checks'. Only from the outlook or appearance of this word, students can't decide which meaning it should be taken unless some certain context is available such as 'His house is on the south bank of the river' or 'He deposited a large sum of money in the bank yesterday'. Supplied with these two sentences when teach the word 'bank', students will never have trouble in telling which on contains the former meaning and which one contains the latter.

Besides letting students distinguish the meaning of polysemic words, the Contextual Teaching Method could be used in teaching the usage of word. For example, when teacher teach 'enjoy', they could use two sentences----'Mike likes watching football match' and 'Jim enjoys watching football match, too'. From these two sentences, students could quickly know the meaning of 'enjoy' is 'like', but also its usage 'enjoy doing something'. Without explaining it, students could get the correct meaning and usage of the word 'enjoy' by themselves.

Language is abstract, complicated and sometimes it is even beyond our capacity of comprehension. So in lexical teaching, it will be a very good way to apply the Contextual Theory to the explanation of the meaning, because the context has the characteristics, such as specific, vivid and concrete etc. The famous linguist Mr. Yu Shuxiang has mentioned that only when the word used in context, it could be memorized and used correctly.[6] Therefore, in lexical teaching, teachers must make full use of this method.

The Behaviorism Theory and LT. The contextualists' view was further strengthened by Bloomfield, who is regarded as the father of American structuralism was greatly influenced by the theories and principles of the Behaviorism Theory. The principles of behaviorism are that if psychology was going to be science, it should study what could be observed publicly and objectively, behavior was the only proper subject of study in psychology. [7] The early behaviorists focused their attention on the topic of learning and they tried to characterize learning in terms of 'stimulus' and 'responses'. As behaviorism developed, its main goal became that of identifying basic learning processes that could be described in terms of 'stimuli' and 'responses'. 
Behaviorists attempted to define the meaning of a language form as the situation in which the speaker utters it and the response it calls forth in contextualism. This view of meaning proposed by Bloomfield is illustrated by his story about Jack and Jill as we are familiar with.

Table 2

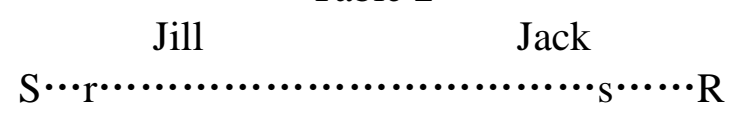

And from this topical example we can draw a conclusion that meaning exists between 'stimulus' and 'response'. This kind of theory could be widely used in lexical teaching, and we can call this method the Behavior Method. That is to say on the occasions in which teachers find it hard to define the meaning, they can use behavior to explain the meaning of word. Teachers use certain kinds of message to arouse certain kinds of behavior effect, and then very easily students can tell the meaning existing between the message, that's the 'stimulus' and 'response'. Teachers can use the stimulus -response to carry the information or to convey the meaning.

This Behavior Method is widely used in teaching verbs. That means when teachers teach a verb, they can do the action which this word means and students can get the correct meaning of the word quickly from teachers' action. As for the word 'nod', it is unnecessary to give the students a very precise definition with a rather long and complicated sentence, because action is much better that word. Teachers just need nod his or her head, and this kind of behavior will cause some kinds of psychological effects on the students, and almost without difficulty, students will catch the meaning of 'nod. This is really a simple and convenient way.

And in English, there are some verbs which have same meaning but the actions, their suggestions are totally different like 'bring' and 'take'. Students find it is hard to distinguish which is which so, when teachers teach these two words, they could use the Behavior Method. Teachers could suppose one place is home, and place many things in the home. And teachers say 'take this book to the classroom.' as while as doing the action when teach the word 'take', then repeat this action again and again. As for 'bring', the teacher could say 'I bring book back home' while performing this action. So students could distinguish these two words from teachers' actions, that 'take' means 'movement something from its original place to another place' and 'bring' suggest 'movement of something from it another place to original place'. The difference between 'bring' and 'take' is obvious through teachers' actions.

\section{Conclusion}

In foreign language teaching, more and more people have noticed the importance of lexical teaching. And only when learners have mastered lots of words, they can really use English fluently and correctly. The Directly Teaching Method, Explanation Teaching Method, Contextual Teaching Method and Behavior Teaching Method are the major for applications of four approaches proposed by various scholars to the study of meaning in lexical teaching. Either one has its own advantages, as well as the shortcomings. Therefore, teachers should make full use of them to make the lexical study more vivid, simple and interesting. Furthermore, these four teaching methods are not single, and they have relations between each other. So, teachers could use one of these methods to teach or combine them in teaching as long as it needed.

Besides these four semantic theories and their applications in lexical teaching, there are still other semantic theories which will help the lexical teaching. And in the near future, it will become the trend to use semantic theories in lexical teaching. 


\section{References}

[1] W.D. Dai, A Concise Course on Linguistics for Students of English, revised ed.. Shanghai Foreign Language and Teaching Press, Shanghai, 1984.

[2] Z.X. He, Modern Linguistics, second ed., Foreign Language Teaching and Research Press, Beijing, 1982

[3] J. Harmer, How to Teach English, first ed., Foreign Language Teaching and Research Press, Beinjin, 2000.

[4] C.K. Ogden \& I.A. Richard, The Meaning of Meaning, 8th ed., Harcourt, Brace \& World, Inc, New York, 1923.

[5] J.R. Firth, Speech, London: Benn’s Sixxpenny Library, 1930.

[6] Information on http://www.guoxue.com/jinxiandai/lvshuxiang/lsx.htm

[7] Ogden, C. K. \& Richards, I. A. 1923. "The Meaning of Meaning." 8th Ed. New York, Harcourt, Brace \& World, Inc 